\title{
EAl Endorsed Transactions

\section{LED based lighting and communications: An emerging technology for a greener more sustainable future}

\author{
A. Burton ${ }^{1, *}$, H. Le Minh ${ }^{1}$, N. Aslam ${ }^{2}$, L. Le ${ }^{3}$ and T. D. Nguyen ${ }^{4}$ \\ ${ }^{1}$ Department of Mathematics, Physics and Electrical engineering, Northumbria University, Newcastle upon Tyne, \\ United Kingdom \\ ${ }^{2}$ Department of Computer and Information Sciences, Northumbria University, Newcastle upon Tyne, United Kingdom \\ ${ }^{3}$ School of Biotechnology, International University, Vietnam National University, Ho Chi Minh City, Vietnam \\ ${ }^{4}$ School of Electrical and Electronic Engineering, International University, Vietnam National University, Ho Chi Minh City, \\ Vietnam
}

\begin{abstract}
The paper discusses on the effect that the growth in our energy consumption as a species is having upon the planet, and how the global lighting and telecommunications industries are major contributors. We demonstrate that through the adoption of LED based lighting combined with visible light communications, substantial economical and power savings by orders of magnitude can be made over existing technologies, contributing towards a greener more sustainable future. The future of LED technology is also discussed with a focus on organic technology, promising increased savings.
\end{abstract}

Keywords: LED, OLED, VLC, green technology.

Received on 22 May 2017, accepted on 18 July 2017, published on 03 August 2017

Copyright (C) 2017 A. Burton et al., licensed to EAI. This is an open access article distributed under the terms of the Creative Commons Attribution licence (http://creativecommons.org/licenses/by/3.0/), which permits unlimited use, distribution and reproduction in any medium so long as the original work is properly cited.

doi: 10.4108/eai.3-8-2017.152982

\section{Introduction}

Estimates, published by the United Nations (UN) have stated that the global human population has increased over the past 100 years from 1.5 to 7.1 billion people [1]. The fastest rate of growth ever experienced in our history. In direct correlation with this, the global demand for energy use over this same period has followed a similar trend. The U.S. energy information administration (EIA) issued the 'International Energy Outlook 2016 (IEO2016)', forecasting a growth in the global energy consumption of 48\% between 2012 and 2040 [2]. Concerns over the rapid growth are raising issues over supply difficulties, the depletion of energy resources and the enormous environmental impacts (global warming, thinning of the ozone layer, climate change etc.). The reliance upon fossil fuels to meet the energy demands is set to continue, predicted to make up $78 \%$ of the energy production by 2040 [2]. The consequences from burning fossil fuels are well known and one of the main contributors of greenhouse gases, and in particular carbon dioxide $\left(\mathrm{CO}_{2}\right)$. A measure of the $\mathrm{CO}_{2}$ emissions is the carbon footprint, or the total amount of greenhouse gases produced directly and indirectly supporting human activities, usually expressed in equivalent tons of $\mathrm{CO}_{2}$. A surprising $2 \%$ of the global carbon footprint is produced by the International Communications Technologies (ICT), of which $0.2 \%$ is due to the mobile networks [3]. This is the equivalent to the worldwide carbon emission of aeroplanes. And powering the lighting infrastructure produces an enormous $19 \%$ of the global carbon emissions (equivalent to almost $70 \%$ of the global carbon emissions through cars) [3]. Therefore, a global effort has begun to find cleaner more sustainable sources of energy and energy usage.

Research and development into solid state devices has revolutionised the lighting industry, leading the way with light emitting diodes (LEDs). Over the past few decades LEDs have matured into brighter, longer lasting and more efficient appliances. In fact, they follow Haitz's law (named after Dr Ronald Haitz, the man who first discovered the phenomenon), that for every decade the cost per lumen decreases by a factor of 10 and the light output generated per LED package increases by a factor of 20, for a given wavelength of light [4]. Modern high brightness LED lamps possess a greater light output per electrical energy input than their forerunners, the 
incandescent and compact fluorescent light (CFL) bulbs. Not only this, but they also possess a longer lifetime further reducing the environmental and monetary impact. Comparisons of the three technologies conducted by USAI Lighting are given in table 1.

Table 1 Comparison, LED vs. Incandescent vs. CFL [5]

\begin{tabular}{|c|c|c|c|}
\hline $\begin{array}{c}\text { Energy efficiency } \\
\text { \& energy costs }\end{array}$ & LED & Incandescent & CFL \\
\hline Life time (average) & $\begin{array}{l}50,000 \\
\text { hours }\end{array}$ & $\begin{array}{l}1,200 \\
\text { hours }\end{array}$ & $\begin{array}{l}8,000 \\
\text { hours }\end{array}$ \\
\hline $\begin{array}{l}\text { Watts of electricity } \\
\text { used }^{*}\end{array}$ & $\begin{array}{c}\text { 6-8 } \\
\text { Watts }\end{array}$ & $\begin{array}{c}60 \\
\text { Watts }\end{array}$ & $\begin{array}{l}13-15 \\
\text { Watts }\end{array}$ \\
\hline $\begin{array}{l}\text { Kilo-Watts of } \\
\text { electricity used }^{* *}\end{array}$ & $\begin{array}{c}329 \\
\mathrm{KWh} / \mathrm{yr}\end{array}$ & $\begin{array}{c}3285 \\
\mathrm{KWh} / \mathrm{yr}\end{array}$ & $\begin{array}{c}767 \\
\mathrm{KWh} / \mathrm{yr}\end{array}$ \\
\hline $\begin{array}{l}\text { Annual operating } \\
\text { cost }^{* *}\end{array}$ & $\begin{array}{l}\$ 32.85 \\
\text { per yr }\end{array}$ & $\begin{array}{c}\$ 328.59 \\
\text { per yr }\end{array}$ & $\begin{array}{l}\$ 76.65 \\
\text { per yr }\end{array}$ \\
\hline $\begin{array}{l}\text { Carbon dioxide } \\
\text { emissions }\end{array}$ & $\begin{array}{c}451 \\
\text { pounds/yr }\end{array}$ & $\begin{array}{c}4,500 \\
\text { pounds/yr }\end{array}$ & $\begin{array}{c}1,051 \\
\text { pounds/yr }\end{array}$ \\
\hline
\end{tabular}

From Table 1, it soon becomes clear that if LEDs where to replace all the existing incandescent and CFL bulbs throughout the ubiquitous global lighting infrastructure there would be enormous savings in energy consumption and benefits to sustainability.

The LED can also benefit the ICT industry, as unlike their counterparts, LEDs are able to be switched on and off many millions of times per second (known as intensity modulation (IM)). At this rate the persistence of the human eye is too slow to perceive any flickering. However, with the suitable electronics high speed changes in light intensity can be detected (direct detection (DD)). Digital information can be encoded onto the light with optical wireless communication (OWC) links being formed through the IM/DD. This next generation of OWC links are known as visible light communications (VLC), providing both illumination and communications simultaneously from the same source. VLC has the capability of complementing Wi-Fi systems, alleviating the already congested radio frequency (RF) spectrum and reducing the relatively high power requirements [6, 7]. Other comparisons of VLC with RF communications are that worldwide, the optical spectrum is license free and unregulated. Also, with the light being unable to penetrate walls, VLC has an inherent high level of security and furthermore this allows for frequency reuse in adjacent rooms without the RF problems of interference. In addition, VLC can offer wireless connectivity in areas that are sensitive to RF radiation such as hospitals [8, 9], chemical plant refineries and aeroplanes $[10,11]$. As the lighting infrastructure is ubiquitous, there are numerous applications for VLC and are constantly growing in number, some of which are discussed in the next section.

The rest of this paper has been organised as follows: Section 2 discusses VLC applications and its possible uses in the modern world, Section 3 analyses the communications power required and makes comparisons with standard Wi-Fi, Section 4 looks to the future of this technology and the adoption of organic LEDs (OLEDs), and finally the conclusions are drawn in Section 5.

\section{VLC Applications}

\subsection{Smart homes and offices}

A smart home or office is defined as a place "that has appliances, lighting, heating, air conditioning, TVs, computers, entertainment audio \& video systems, security, and camera systems that are capable of communicating with one another and can be controlled remotely by a time schedule, from any room in the home, as well as remotely from any location in the world by phone or internet" [12]. Smart homes offer increased comfort, safety and security. VLC is an ideal candidate to be integrated into such environments controlling and communicating with the appliances [13]. Dimming control and support is also essential for the smart homes/offices to create moods, increasing the aesthetic value but most importantly to conserve energy. This has attracted numerous researchers with possible solutions ranging from hybrid pulse width modulation (HPWM) techniques [7, 14, 15], multiple input multiple output (MIMO) systems [16] and variable rate modulation and coding [17].

\subsection{RF sensitive areas}

Hospitals, aeroplanes, chemical refinement plants and underground mines are a few of the areas sensitive to RF radiation, where interference with equipment or the generation of sparks could prove catastrophic. Hence VLC is the ideal technology to employ; the lighting already exists in these environments and produces no adverse effects or intrusion $[8-11,18]$.

\subsection{Vehicular networks \& intelligent transport systems}

The clear majority of modern vehicles use LEDs as their primary source of illumination due to the substantial energy savings and increased lifetimes; as are the road side street lamps and traffic signalling lights. The integration of VLC into these systems is the next natural and logical progression. Vehicle to Vehicle communications (V2V) for road safety and ad-hoc networks using the headlights are being developed [1923], alongside intelligent transport systems linking the vehicles to the transportation infrastructure [24, 25].

\subsection{Underwater communication}


Wireless underwater communications have always been a challenge because RF cannot propagate in this environment; however light beams can. Research is currently underway to bring VLC into this location for deep sea diver safety and communication [26, 27], communication and localisation of robotically operated vehicles [28], sensor networks [29] and long distance single photon detection communication systems [30].

\subsection{Location based systems (Indoor \& outdoor)}

Location estimation and positioning systems both indoor and outdoor are important both to guide you where you are or going to, and even autonomous robot control. With many techniques postulated [31-33], VLC can offer accurate positional data without the need to deploy an additional sensor network infrastructure, and use the lighting that already exists.

\section{Investigation into VLC transmit Power requirements}

The communications power requirements for a typical VLC system can be calculated through the power link budget. The link budget is defined by:

$$
\operatorname{Pr}_{\mathrm{dBm}}=P t x_{d B m}+H(0)_{\mathrm{dB}}-L m_{\mathrm{dB}} \text {, }
$$

where $\operatorname{Pr} x_{\mathrm{dBm}}$ is the received power in $\mathrm{dBm}, P t x_{\mathrm{dBm}}$ is the transmit power in $\mathrm{dBm}, H(0)_{\mathrm{dB}}$ is the line of sight (LOS) DC gain in $\mathrm{dB}$, and finally $L m_{\mathrm{dB}}$ is the link margin also in $\mathrm{dB}$. The link margin is designed to take care of any miscellaneous losses such as slight angular misalignment or fading losses. The channel gain $H(0)_{\mathrm{dB}}$ is given by [34]:

$$
\begin{array}{r}
H(0)=\left\{\begin{array}{r}
\frac{(m+1) A_{d e t}}{2 \pi d_{0}^{2}} \cos ^{m}(\phi) g(\psi) \cos (\psi) \\
\text { for } \psi \leq \Psi_{c}, \\
\text { otherwise }
\end{array},\right. \\
H(0)_{\mathrm{dB}}=10 \log _{10}(H(0)),
\end{array}
$$

where $m$ is the LED Lambertian order and is related to the LEDs semi angle at half illuminance $\Phi_{\text {LED }}(\mathrm{m}=$ $\left.1 / \log _{2}\left(\cos \left(\Phi_{\mathrm{LED}}\right)\right)\right), A_{d e t}$ is the detectors active area $\left(\mathrm{m}^{2}\right)$, $d_{0}$ is the distance between the transmitter and receiver $(\mathrm{m}), \phi$ is the angle of irradiance, $g(\psi)$ is the concentrating lens gain related to the materials refractive index $n$ and the field of view $\Psi_{\mathrm{c}}\left(g(\psi)=n^{2} / \sin ^{2}\left(\Psi_{\mathrm{c}}\right)\right)$, and finally $\psi$ is the angle of incidence. All parameters of the DC gain are depicted in Figure 1. Through substitution of the received power $P r x_{\mathrm{dBm}}$, with the receiver sensitivity (or the required received power) $P D s_{\mathrm{dBm}}$, and rearranging (1), it is possible to find the minimum required transmit power, i.e.:

$$
P t x_{d B m}=P D s_{\mathrm{dBm}}-H(0)_{\mathrm{dB}}+L m_{\mathrm{dB}} .
$$

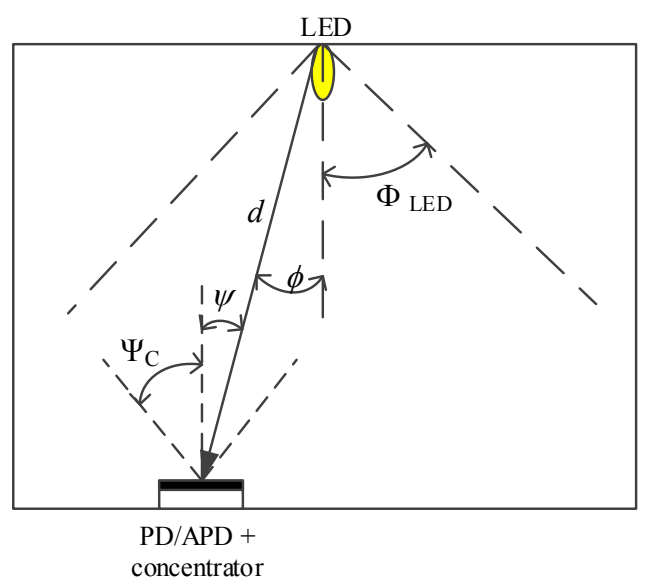

Figure 1 VLC LOS DC gain model parameters.

The simulation parameters are outlined in Table 2.

Table 2 Simulation parameters

\begin{tabular}{l|l}
\hline \hline Simulation parameter & Value \\
\hline \hline LED semi angle at half illuminance, $\Phi_{\mathrm{LED}}$ & $60 \mathrm{deg}$ \\
\hline Detector area, $A_{\text {det }}$ & $1 \mathrm{~cm}^{2}$ \\
\hline Concentrator refractive index (glass), $n$ & 1.5 \\
\hline Receiver FOV, $\Psi_{\mathrm{c}}$ & $15 \mathrm{deg}$ \\
\hline Distance between LED and receiving plane & $2 \mathrm{~m}$ \\
\hline Receiver sensitivity, $P D s_{\mathrm{dBm}}$ & $\mathrm{PIN}=-30 \mathrm{dBm}$ \\
& $\mathrm{APD}=-40 \mathrm{dBm}$ \\
\hline
\end{tabular}

\subsection{Simulation results and discussion}

The first set of results in figure 2 show the channel DC gain over a receiving plane (RP) with an area of $9 \mathrm{~m}^{2}(3 \mathrm{x}$ $3 \mathrm{~m}^{2}$ ) using the parameters outlined in Table 2. The transmitting LED is placed at the centre of the transmitting plane (coordinates 0,0 ). It is assumed that the receiving $\mathrm{PD}$ is pointing with the normal directed at the transmitting plane as shown in Figure 1. The channel DC gain ranges between -35.73 and $-36.33 \mathrm{~dB}$, equivalent to 267 and $233 \mu \mathrm{W} / \mathrm{W}$. It also shows that the communications foot print covers an area approximately $0.79 \mathrm{~m}^{2}$ stretching $0.5 \mathrm{~m}$ symmetrically around the centre point. 


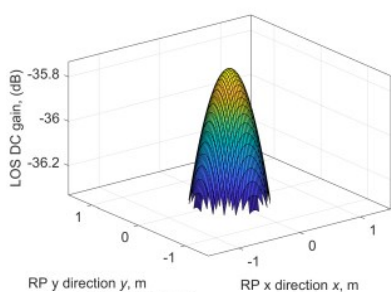

(a)

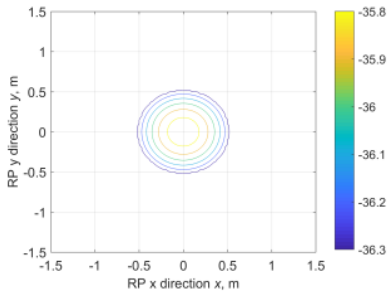

(b)
Figure 2 (a) surface plot and (b) contour plot of the LOS DC gain along the receiving plane

It must be noted that it may not always possible to have the receiving PD normal to be pointing directly at the transmitting plane. For comfort reasons and ease of access, it may be necessary to tilt the receiver (through angle $\alpha$ ) if it is fixed to a device such as a laptop or a tablet. This is demonstrated in Figure 3 where the PDs are situated on (a) the laptop lid (the normal shown in the dotted line), and (b) the front of the tablet (shown in black)). This angular misalignment has an effect on Eq (2) and altering the DC gain of the channel.

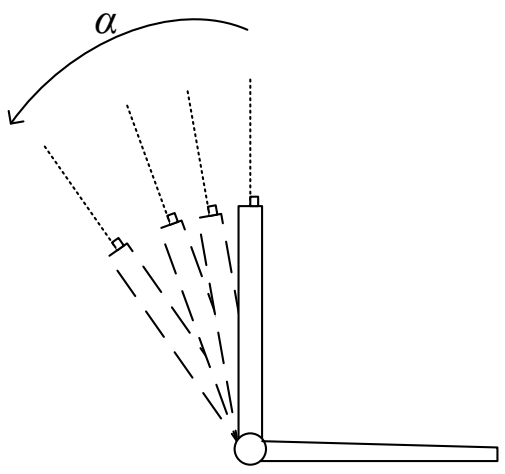

(a)

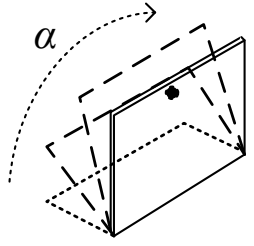

(b)
Figure 3 the angular misalignment $\alpha$ of the PD on (a) Laptop and (b) Tablet

The misalignment angle has been simulated for $\alpha \in\{5$, 20 \} degrees. The results are shown in Figure 4.

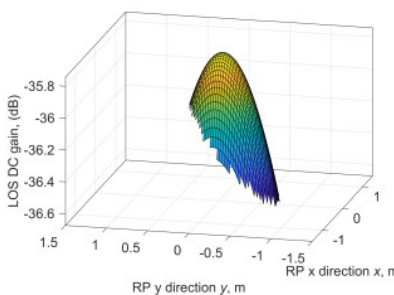

(a)

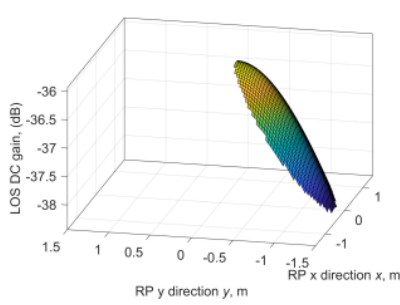

(c)

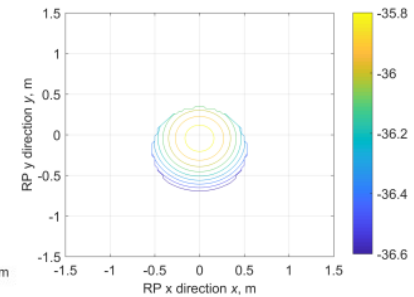

(b)

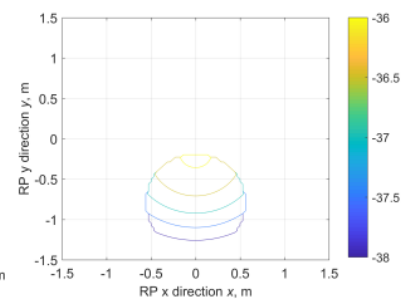

(d)
Figure $4(a-b)$ surface and contour plot for $\alpha=5^{\circ}$, and $(c-d)$ surface and contour plot for $\alpha=20^{\circ}$

Figure 4 demonstrates how the angle $\alpha$ not only effects the maximum DC gain of the channel but also the distance and area through which the OWC link is achievable. For the case of $\alpha=20^{\circ}$ the link distance has increased to around $1.3 \mathrm{~m}$ over the $0.5 \mathrm{~m}$ of the case in Figure 1 where $\alpha=0^{\circ}$. However, the DC gain has dropped by $2 \mathrm{~dB}$. Thus allowing for a link margin of $2 \mathrm{~dB}$ in Eq (4), it is possible to take the case for $\alpha=0^{\circ}$ (the best condition), and ensure that the link is available for all eventualities of $\alpha$ up to $20^{\circ}$. Hence, a transmit power of 8.2 and $-1.8 \mathrm{dBm}$ would be required by the PIN and APD links respectively (equivalent to $6.8 \mathrm{~mW}$ and $680 \mu \mathrm{W}$ ).

\subsection{Comparing VLC and Wi-Fi transmit power}

Table 3 outlines the transmission power of conventional and low power 802.11 Wi-Fi standards [35], and the equivalent transmission power required through VLC. The numbers of OWC links needed to reach the same power of the Wi-Fi links are also outlined.

Table 3 Comparison of the transmit power required by VLC and Wi-Fi

\begin{tabular}{c|cccc}
\hline & \multicolumn{2}{|c}{ Wi-Fi } & PIN & APD \\
& conventional & low power & & \\
\hline \hline Power $(\boldsymbol{m} \boldsymbol{W})$ & 820 & 350 & 6.8 & 0.68 \\
\hline Conventional" & $\sim$ & $\sim$ & 117 & 1,200 \\
\hline Low Power & $\sim$ & $\sim$ & 50 & 514 \\
\hline \multicolumn{2}{r}{ Number of PDs required in comparison to } \\
\end{tabular}


From Table 3, it once again becomes clear that through the adoption of VLC for high speed wireless communications considerable savings can be made. Even for the case of the low power Wi-Fi standard the equivalent number of PDs required (both PIN and APD) would far exceed those needed to cover the same footprint.

\section{Future possibilities}

The applications for VLC are continuously growing in number with new uses being discovered on a regular basis. The LED technology is also advancing, incessantly producing brighter and more energy efficient devices. Although they may soon be superseded by the cheaper to manufacture, more efficient, large area organic LED (OLED) that can be made into any shape, and dependent upon the substrate they are fabricated on can also be made to be flexible. OLEDs have already penetrated the commercial market in televisions, mobile phones, media players, watches, advertisement signage, panel lighting and have even been incorporated into safety clothing. Large companies, such as Phillips, Samsung, Motorola and Sony Ericsson are currently investing millions of dollars into their OLED research and development programs. This has also spurred on the communications industry and academics to incorporate OLED technology into VLC [36]. However, it must be noted that OLEDs and especially large area panel OLEDs cannot be modulated at the high speeds achievable by their nonorganic counterparts, and a lot of effort is being spent investigating equalisation techniques overcome this [37, 38]. But it must also be noted that not all VLC applications require high speed data transmission. There have also been studies conducted on the suitability of OLED panelling as a lighting and communications device within the home. It was found that with the optimal layout and positioning of the OLED panels, and with the suitable driving electronics, high speed data broadcasts $(>10$ Mbps) at standard illumination levels ( $>500$ Lux) can be achieved [39].

\section{Conclusions}

Carbon emissions are one of the biggest issues of the $21^{\text {st }}$ century and the devastation it is causing to our planet. And with the current population growth rate, the problem is only set to get worse. Therefore, it is our duty as a collective species to increase our efforts towards reducing $\mathrm{CO}_{2}$ emissions. We can achieve this on an individual basis through the adoption of LED technology and the abstainment from incandescent and CFL bulb use in our homes and offices. This paper has shown that with LED and OLED technology further advancements in the reduction of our carbon footprint can be made in almost every aspect of our modern lives and that VLC can dramatically reduce the power drain by an order of magnitude that is currently produced by the ICT. Employing LED spotlights for the data communications would require more than 117 and 50 PIN links; or, 1,200 and 514 APD links to surpass both Wi-Fi standards. Hence VLC is a viable, future proof method for a greener more sustainable future.

\section{Acknowledgements}

The author Andrew Burton would like to acknowledge the gLink project on green sustainable technologies for funding the research carried out in this paper.

\section{References}

[1] Roser, M. and Ortiz-Ospina, E.. (10/04/2017). World Population Growth. Available:

https://ourworldindata.org/world-population-growth/

[2] (23/03/2017). U.S. Energy Information Administration (EIA), International Energy Outlook. Available: https://www.eia.gov/outlooks/ieo/pdf/0484(2016).pdf

[3] I. Digiworld. Femtocells: Major Telecom equipment vendors, operators showing greater interest in femtocell market. Available: http://www.idate.org/.

[4] Haitz, R. and Tsao, J. Y.,(2011) "Solid-state lighting: 'The case' 10 years after and future prospects," physica status solidi (a), vol. 208, pp. 17-29..

[5] U. Lighting. (2016, 06/02/2017). Comparison Chart LED Lights vs. Incandescent Light Bulbs vs. CFLs. Available: http://www.usailighting.com/stuff/contentmgr/files/1/92ffe b328de0f4878257999e7d46d6e4/misc/lighting_compariso n_chart.pdf

[6] Li-Fi Gets ready To Compete With Wi-Fi. IEEE Spectrum. pp. 13-16.

[7] Shao, S., Khreishah, A., and Khalil, I., (2016)"Joint link scheduling and brightness control for greening VLC-based indoor access networks," IEEE/OSA Journal of Optical Communications and Networking, vol. 8, pp. 148-161.

[8] Tan, Y. Y., Jung, S. J., and Chung, W. Y.,(2013) "Real time biomedical signal transmission of mixed ECG Signal and patient information using visible light communication," in 2013 35th Annual International Conference of the IEEE Engineering in Medicine and Biology Society (EMBC), pp. 4791-4794.

[9] Cahyadi, W. A., Jeong, T. I., Kim, Y. H., Chung, Y. H., and Adiono, T., (2015)"Patient monitoring using Visible Light uplink data transmission," in 2015 International Symposium on Intelligent Signal Processing and Communication Systems (ISPACS), pp. 431-434.

[10] Chan, E.,(2012) "Wireless optical links for airplane applications," in 2012 IEEE Photonics Society Summer Topical Meeting Series, pp. 76-77.

[11] Tagliaferri, D. and Capsoni, C.,(2016) "SNIR predictions for on-aircraft VLC systems," in 2016 International Conference on Broadband Communications for Next Generation Networks and Multimedia Applications (CoBCom), pp. 1-7.

[12] (07/02/2017). WHAT IS A SMART HOME? Available: $\mathrm{http}: / /$ www.smarthomeusa.com/smarthome/

[13] Tiwari, S. V., Sewaiwar, A., and Chung, Y. H., (2015)"Smart home technologies using Visible Light 
Communication," in 2015 IEEE International Conference on Consumer Electronics (ICCE), pp. 379-380.

[14] Stevens, N. and Strycker,(2016) L. D., "Single Edge Position Modulation as a Dimming Technique for Visible Light Communications," Journal of Lightwave Technology, vol. 34, pp. 5554-5560.

[15] Zafar, F., Karunatilaka, D., and Parthiban, R., (2015) "Dimming schemes for visible light communication: the state of research," IEEE Wireless Communications, vol. 22 , pp. 29-35

[16] Wang, Z., Guo, C., Yang, Y., and Li, Q.,(2016) "A Novel Dimming Scheme for Indoor MIMO Visible Light Communication Based on Antenna Selection," in 2016 IEEE 83rd Vehicular Technology Conference (VTC Spring), pp. 1-5.

[17] Rajagopal, S., Roberts, R. D., and Lim, S. K., (2012)"IEEE 802.15.7 visible light communication: modulation schemes and dimming support," IEEE Communications Magazine, vol. 50, pp. 72-82.

[18] Song, J., Wenbo, D., Fang, Y., Hui, Y., Wang, J., Xiaofei, W., et al.,(2014) "Indoor hospital communication systems: An integrated solution based on power line and visible light communication," in 2014 IEEE Faible Tension Faible Consommation, pp. 1-6.

[19] Jong-Ho, Y., Rimhwan, L., Jun-Kyu, O., Hyun-Wook, S., Ju-Young, K., Hyeon-Cheo, K. 1, et al.,(2013) "Demonstration of vehicular visible light communication based on LED headlamp," in 2013 Fifth International Conference on Ubiquitous and Future Networks (ICUFN), pp. 465-467.

[20] Turan, B., Ucar, S., Ergen, S. C., and Ozkasap, O.,(2015) "Dual channel visible light communications for enhanced vehicular connectivity," in 2015 IEEE Vehicular Networking Conference (VNC), pp. 84-87.

[21] Siddiqi, K., Raza, A. D., and Muhammad, S. S., (2016) "Visible light communication for $\mathrm{V} 2 \mathrm{~V}$ intelligent transport system," in 2016 International Conference on Broadband Communications for Next Generation Networks and Multimedia Applications (CoBCom), pp. 1-4.

[22] Uysal, M., Ghassemlooy, Z., Bekkali, A., Kadri, A., and Menouar, H.,(2015) "Visible Light Communication for Vehicular Networking: Performance Study of a V2V System Using a Measured Headlamp Beam Pattern Model," IEEE Vehicular Technology Magazine, vol. 10, pp. 45-53.

[23] Uçar, S., Ergen, S. Ç., and Ö, Ö, (2016) "Visible light communication in vehicular ad-hoc networks," in 2016 24th Signal Processing and Communication Application Conference (SIU), pp. 881-884.

[24] Marè, R. M., Cugnasca, C. E., Marte, C. L., and Gentile, G., (2016)"Intelligent transport systems and visible light communication applications: An overview," in 2016 IEEE 19th International Conference on Intelligent Transportation Systems (ITSC), pp. 2101-2106.

[25] Yao, D., Luxi, L., Haoyu, W., Zhida, L., Shihao, W., and Jianhua, S., (2015) "Visible light communication based collision avoidance scheme for vehicle lanechanging in Intelligent Transport Systems," in 2015 14th International Conference on Optical Communications and Networks (ICOCN), pp. 1-3.

[26] Ahmad, Z., Geisar, P., Salih, O., and Rajbhandari, S., (2016) "Design of a visible light communication system for deep sea divers based on analogue frequency modulation," in 2016 10th International Symposium on Communication Systems, Networks and Digital Signal Processing (CSNDSP), pp. 1-5.
[27] Das, A. K., Ghosh, A., Vibin, A. M., and Prince, S. ,2012) "Underwater communication system for deep sea divers using visible light," in 2012 Photonics Global Conference (PGC), pp. 1-3.

[28] Rust, I. C. and Asada, H. H., (2012)"A dual-use visible light approach to integrated communication and localization of underwater robots with application to nondestructive nuclear reactor inspection," in 2012 IEEE International Conference on Robotics and Automation, pp. 2445-2450.

[29] Chang, S. H., Pereira, R., and Shih, K. P., (2015)"A Novel Network Topology in Underwater Visible Light Sensor Networks," in 2015 IEEE International Conference on Computer and Information Technology; Ubiquitous Computing and Communications; Dependable, Autonomic and Secure Computing; Pervasive Intelligence and Computing, pp. 801-805.

[30] Wang, C., Yu , H. Y., and Zhu, Y. J., (2016)"A Long Distance Underwater Visible Light Communication System With Single Photon Avalanche Diode," IEEE Photonics Journal, vol. 8, pp. 1-11.

[31] Do, T.-H. and Yoo, M., (2016)"An in-depth survey of visible light communication based positioning systems," Sensors, vol. 16, p. 678.

[32] Yang, S. H., Jung, E. M., and Han, S. K., (2013) "Indoor Location Estimation Based on LED Visible Light Communication Using Multiple Optical Receivers," IEEE Communications Letters, vol. 17, pp. 1834-1837.

[33] Do, T. H. and Yoo, M., (2015) "Potentialities and challenges of VLC based outdoor positioning," in 2015 International Conference on Information Networking (ICOIN), pp. 474-477.

[34] Komine, T. and Nakagawa, M., (2004)"Fundamental analysis for visible-light communication system using LED lights," IEEE Transactions on Consumer Electronics, vol. 50, pp. 100-107.

[35] Vasseur, J.-P. and Dunkels, A.,(2010) Interconnecting smart objects with ip: The next internet: (Burlington, MA: Kaufmann).

[36] Chvojka, P., Dvorak, P., Pesek, P., Zvanovec, S., Haigh, P. A., and Ghassemlooy, Z.,(2016) "Characterization of the organic LED based visible light communications," in 2016 10th International Symposium on Communication Systems, Networks and Digital Signal Processing (CSNDSP), pp. $1-4$.

[37] Haigh, P. A., Ghassemlooy, Z., Papakonstantinou, I., and Le Minh, H.,(2013) "2.7 Mb/s With a 93-kHz White Organic Light Emitting Diode and Real Time ANN Equalizer," IEEE Photonics Technology Letters, vol. 25, pp. 1687-1690.

[38] Thai, P. Q., Thanh, N. T., Shigeru, S., Liu, J., and Wende, Z., (2015)"127.5 kbps Transmission using OLED with 7 $\mathrm{kHz} 3 \mathrm{~dB}$ modulation bandwidth in visible light communication system," in 2015 International Conference on Advanced Technologies for Communications (ATC), pp. 389-393.

[39] Chun, H., Chiang, C. J., Monkman, A., and O'Brien, D., (2013)"A Study of Illumination and Communication using Organic Light Emitting Diodes," Journal of Lightwave Technology, vol. 31, pp. 3511-3517. 